\title{
Menyiapkan Lulusan D3Tata Busana Teknologi Industri Fakultas Teknik UM yang Berkualitas Menyongsong Pemberlakuan Masyarakat Ekonomi Asean (MEA)2015
}

\author{
Agus Hery Supadmi Irianti (Dosen Jurusan Teknologi Industri FT-UM) \\ Email:agushery_um52@yahoo,co,id
}

\begin{abstract}
Abstrak. Pemberlakuan Masyarakat Ekonomi Asean (MEA) pada tahun 2015 membawa dampak terjadinya arus barang jasa, investasi dan tenaga kerja terampil yang bebas serta aliran modal yang bebas antar negara di kawasan ASEAN. Persaingan tenaga kerja terampil yang diakui menjadi modal bangsa Indonesia khususnya lembaga pendidikan yang mencetak lulusannya agar siap bersaing menghadapai diberlakukannya MEA 2015. Terkait dengan hal tersebut kualitas lulusan khususnya lulusan Pendidikan Tata Busana perlu mendapat perhatian dan pemikir an yang serius guna menghadapi pemberlakuan MEA. Permasalahan nya: kualitas dalam dunia pendidikan bukan saja mengimplemen tasikan KKNI ke dalam kurikulum atau mata kuliah serta penetapan Standar Nasional Perguruan Tinggi (SNPT) saja, akan tetapi pengakuan kompetensi lulusan secara yuridis. Metode yang dapat dilakukan untuk mengatasi permasalahan tersebut adalah meningkatkan kualitas lulusan D3 tata busana melalui pengakuan yuridis kompetensi lulusan yang dalam hal ini dibuktikan dengan bukti sertiikasi keahlian yang dilakukan oleh Badan Nasional Sertifikasi Profesi.
\end{abstract}

Kata Kunci: MEA, Lulusan D3 Tata Busana, Kualitas

\section{Pendahuluan}

Masyarakat Konferensi Tingkat Tinggi (KTT) ASEAN pada Desember 1997 di Kuala Lumpur, Malaysia melahirkan inisiatif pembentukan integrasi kawasan ASEAN atau komunitas masyarakat ASEAN melalui ASEAN Vision 2020 saat berlangsungnya ASEAN Second Informal Summit. Inisiatif ini kemudian diwujudkan dalam bentuk roadmapjangka panjang yang berna ma Hanoi Plan of Action yang disepakati pada 1998. Pada KTT selanjutnya yang diselenggarakan di Bali pada 7 Oktober 2003 dideklarasikan pemberlakuan Masyarakat Ekonomi Asia (MEA) pada tahun 2015 (Suroso, 2015). MEA memuat 4 pilar utama yaitu 1) ASEAN sebagai pasar tunggal dan berbasis produksi tunggal yang didukung dengan elemen aliran bebas barang jasa investasi, tenaga kerja terdidik dan aliran modal yang lebih bebas, 2) ASEAN sebagai kawasan dengan daya saing ekonomi tinggi dengan elemen peraturan kompetisi, perlindungan konsumen, hak atas kekayaan intelektual, pengembangan infra 
struktur perpajakan dan e-commerrce, 3) ASEAN sebagai kawasan dengan pengembangan ekonomi yang merata dengan elemen pengembangan usaha kecil dan menengah dan prakarsa integrasi ASEAN untuk negara negara Cambodia, Myanmar, Laos, dan Vietnam, 4) ASEAN sebagai kawasan yang terintegrasi secara penuh dengan perekonomian global dengan elemen pendekatan yang koheren dalam hubungan ekonomi di luar kawasan, dan meningkatkan peran serta dalam jejaring produksi global. Pemberlakuan MEA tersebut memberikan Dampak positif maupun negatif yang timbul dari pemberlakuan Masyarakat Ekonomi ASEAN ( MEA) yaitu, terjadinya arus barang jasa, investasi dan tenaga kerja terampil yang bebas serta aliran modal yang bebas antar negara di kawasan ASEAN. Sisi positif yang dapat dijadikan peluang adalah jumlah penduduk di Indonesia yang pada tahun 2013 mencapai 248,8 juta dengan jumlah angkatan kerja pada Februari 2014 mencapai 1253 juta ( Badan Pusat Statistik, 2014). Dari data tersebut jumlah angkatan kerja sangat fantastik jika semua dapat terserap diberbagai lapangan kerja baik di dalam maupun di luar negeri. Namun akan menjadi bencana jika jumlah angka tersebut tidak dapat terserap di dunia kerja yang ada. Kondisi angkatan kerja yang tidak memiliki keterampilan yang teruji melalui sertiikasi akan dapat menyebabkan kendala tersendiri dikemudian hari. Makna dari kalimat diatas adalah rendahnya kualitas angkatan kerja. Hal ini dapat berbahaya karena akan berhadapan dengan tenaga asing dari luar negeri yang sudah memiliki pengakuan legal tentang kompetensi atau keahliannya. Selain hal tersebut Dampak lainnya adalah dapat memperluas ruang investasinya antar negara anggota ASEAN. Sebaliknya Indonesia juga dapat menarik investasi asing dari investor ASEAN. Namun dibalik itu semua masih terdapat kelemahan yang ada yaitu tentang kualitas infra struktur di Indonesia yang masih tertinggal dibanding negara lain di ASEAN seperti Singapura Malaysia, Brunei dan Thailand (Global Competitiveness Index, 2014) . Daya saing ASEAN masih terdapat kesenjangan yang secara riil dapat digambarkan sebagai berikut:

Tabel 1. Daya Saing Negara Anggota ASEAN Tahun 2012-2-13

\begin{tabular}{lllll}
\hline Negara & Rangking daya saing & Basic & $\begin{array}{l}\text { Effisiensi } \\
\text { Enhancers }\end{array}$ & $\begin{array}{l}\text { Inovation \& } \\
\text { Sophistication }\end{array}$ \\
\hline Indonesia & 50 & 58 & 58 & 40 \\
Malaysia & 25 & 27 & 23 & 23 \\
Singapura & 2 & 1 & 1 & 11 \\
Thailand & 38 & 45 & 47 & 55
\end{tabular}




\begin{tabular}{lllll} 
Philipina & 65 & 80 & 65 & 64 \\
Brunei D & 28 & 21 & 68 & 62 \\
Cambodia & 85 & 97 & 85 & 72 \\
Laos & na & $\mathrm{Na}$ & $\mathrm{Na}$ & $\mathrm{Na}$ \\
Myanmar & $\mathrm{na}$ & $\mathrm{Na}$ & $\mathrm{Na}$ & $\mathrm{Na}$ \\
Vietnam & 75 & 91 & 71 & 90 \\
\hline
\end{tabular}

Sumber World Economic Forum 2012-2013 dalam Jurnal kajian Lemhanas RI edisi 16 November 2013

Sementara itu penyelenggaraan Pendidikan di Indonesia mengambil peranan yang tidak kalah pentingnya dalam menghasilkan angkatan kerja melalui lulusan yang memiliki daya saing kompeten dan terakui. Terkait dengan pentingnya peran lembaga pendidikan dalam mencetak tenaga yang berkualitas dan mampu bersaing menghadapi MEA. Seperti kita ketahui bahwa Visi Misi Lembaga penyelenggara pendidikan merupakan pedoman dalam penyelenggaraan pendidikan dalam arti yang luas. Penyelenggara pendidikan secara hirarki berada di tingkat prodi seperti halnya di Prodi D3 Tata busana FT UM. Misi Prodi D3 Tata Busana Jurusan TI FT-UM (1) Menghasilkan sumber daya manusia (SDM) yang berkualitas di bidang Tata Busana sesuai dengan kebutuhan dunia usaha/industri, dan kebutuhan pembangunan, dengan menerapkan sistem pendidikan yang efektif, efisien, dan fleksibel. (2) Mengembangkan ilmu pengetahuan dan teknologi Tata Busana melalui kegiatan penelitian dan pengembangan yang menghasilkan karya akademik dan temuantemuan yang berbobot dan bermakna. (3) Menerapkan ilmu pengetahuan dan teknologi Tata Busana yang berguna bagi kesejahteraan masyarakat dan kemanusiaan. (4) Menjadi pusat informasi dalam bidang pengembangan teknologi Tata Busana dan kewirausahaan berbasis teknologi Tata Busana. (5) Mengembangkan kerjasama dengan lembaga, baik di dalam maupun di luar UM dalam rangka pengembangan pendidikan, penelitian maupun pengabdian kepada masyarakat di bidang Tata Busana. (Katalog Jurusan TI, 2014). Terkait dengan penyelenggaraan prodi D3 Tata busana juga dijelaskan tujuan nya adalah: (1) Melaksanakan kegiatan pendidikan dan pelatihan untuk menghasilkan SDM yang berkualitas di bidang Tata Busana sesuai dengan kebutuhan dunia usaha/industri dan kebutuhan pembangunan, dengan menerapkan kurikulum berbasis 
kompetensi. (2) Mengembangkan sarana dan prasarana praktikum untuk meningkatkan keterampilan kejuruan lulusan. (3) Melaksanakan kegiatan sertifikasi lulusan untuk meningkatkan daya saingnya di pasar kerja. (4) Menjalin kerjasama dengan berbagai dunia usaha/ industri untuk meningkatkan kualitas pelaksanaan pembelajaran baik teori, praktikum, maupun praktik industri, termasuk pelaksanaan sertifikasi dan penempatan lulusan. (5) Melaksanakan kegiatan penelitian dan pengembangan ilmu pengetahuan dan teknologi di bidang Tata Busana. (6) Melaksanakan kegiatan pengabdian kepada masyarakat di bidang Tata Busana untuk meningkatkan kesejahteraan masarakat dan kemanusiaan. Prodi D3 Tata Busana merupakan pendidikan Vokasi, dimana beberapa ciri dari pendidikan vokasi adalah pembelajaran berbasis kompetensi, penyelenggaraan kegiatan belajar mengajar mengguna kan sistem ganda yaitu pembelajaran dilakukan di dalam perguruan tinggi dan diluar perguru an tinggi dalam bentuk Praktik Industri.

Kompetensi lulusan Prodi D3Tata busana menurut katalog jurusan TI FTUM dapat dijabarkan menjadi 2 yaitu sebagai berikut: a) Supervisor pada Industri Busana dan b) Pengelola Usaha Busana. Kompetensi Supervisor didukung oleh beberapa sub kompetensi sbb : (1) Memiliki kemampuan menggunakan alat jahit dengan tepat. (2) Memiliki pengetahuan memilih bahan. (3) Memiliki kemampuan membuat desain produksi dan desain illustrasi. (4) Memiliki kemampuan membuat pola busana (konstruksi, standar). (5) Memiliki kemampuan membuat pola secara grading. (6) Memiliki kemampuan memotong bahan sesuai pola. (7) Memiliki kemampuan menjahit sesuai model. (8) Memiliki kemampuan membuat pola draping. (h) Memiliki kemampuan packing, labeling. (9) Memiliki kemampuan membuat perencanaan produksi sesuai order (desain, bahan, pelengkap). (10) Memiliki kemampuan memeriksa kualitas pekerjaan (persiapan, produksi: pola, potong, jahit, dan penyelesaian, Packing dan labeling, kecepatan dan ketepatan kerja, dll) sesuai standar. (11) Memiliki kemampuan tentang kepengawasan (supervisi) pada perencanaan produksi, proses, dan pengendalian mutu). (12) Memiliki kemampuan melakukan komunikasi dengan baik. (13) Memiliki kemampuan melakukan evaluasi terhadap kinerja dan kualitas produk. (14) Memiliki pengetahuan dan kemampuan tentang K3 dan pelaksanaannya. (15) Memiliki kemampuan menggambar desain sketsa. (16) Memiliki kemampuan membuat desain motif. (17) Memiliki kemampuan membuat desain hiasan. (18) Memiliki kemampuan membuat desain pelengkap busana. Sedangkan kompetensi Pengelola Usaha Busana didukung oleh sub kompetensi : (1) Pe- 
ngelola Usaha Modiste; memiliki kemampuan membuat desain sketsa; memiliki kemampuan membuat pola konstruksi dan pecah model; memiliki kemampuan membuat busana dengan teknik penyelesaian Madya; memiliki kemampuan membuat perencanaan usaha modiste (meliputi: Hpp, jenis produk dll); memiliki kemampuan melaksanakan pengawasan dan pengendalian usaha modiste (mengelola usaha modiste). (2) Pengelola Usaha Busana Industri; memiliki kemampuan membuat desain; memiliki kemampuan grading pola; memiliki kemampuan membuat busana dengan teknik penyelesaian busana industri; memiliki kemampuan membuat perencanaan usaha industri busana (desain, pola, potong, Hpp, jenis produk dIl); memiliki kemampuan pengawasan dan pengendalian usaha industri. (3) Pengelola Usaha Butik; memiliki kemampuan membuat desain sketsa; Memiliki kemampuan membuat pola konstruksi; memiliki kemampuan membuat pola drapping; memiliki kemampuan membuat dan memilih pelengkap busana; memiliki kemampuan membuat busana dengan teknik penyelesaian adi busana; memiliki kemampuan membuat perencanaan usaha butik (meliputi: strategi pemasaran, sdm, penentuan, Hpp, jenis produk, dII); memiliki kemampuan melaksanakan pengawasan dan pengendalian usaha Butik (mengelola usaha butik). Sebagai supervisor dibidang industri busana sangat banyak kompetitornya, jika Prodi D3 Tata Busana tidak membekali dengan kualitas lulusan dalam bersaing maka akan dapat menambah deret panjang angka tenaga kerja dengan mutu rendah sehingga sulit bersaing dengan sumber daya manusia lain dari luar negara di ilayah ASEAN.

Gambaran pelaksanaan pembelajaran dalam meningkatkan kualitas lulusan saat ini sudah dilakukan, diantaranya dengan memasukkan KKNI dalam kurikulum dan pembelajaran yang diharapkan dapat menyesuaikan dengan kebutuhan tempat kerja, melibatkan stake holder dan alumni dalam menyusun kurikulum. Pelaksanaan pembelajaran di tempat kerja sesungguhnya di luar bangku kuliah juga sudah dilakukan. Namun kendala yang saat ini ada adalah belum adanya pengakuan legal tentang keahlian yang dimiliki oleh mahasiswa. Munculnya PP no 49 tahun 2014 tentang standar Nasional Perguruan tinggi juga merupakan salah satu upaya yang dilakukan pemerintah untuk meningkatkan kualitas pendidikan di Perguruan Tinggi. Namun demikian kita semua tau bahwa kondisi mutu pendidikan tenaga kerja masih rendah, di mana hingga Febuari 2014 jumlah pekerja berpendidikan SMP atau dibawahnya tercatat sebanyak 76,4 juta orang atau sekitar 64 persen dari total 118 juta pekerja di Indonesia 
(Fadli 2014). Hal ini pasti akan menjadi hambat an dalam menyongsong diberlakukannya Masyarakat Ekonomi Asean ( MEA) pada tahun 2015 ini.

\section{Permasalahan}

Dari Paparan diatas dapat disimpulkan bahwa permasalahan dunia pendidikan dalam mengatasi diberlakukannya masyarakat ekonomi ASEAN (MEA) adalah: (1) Banyaknya jumlah angkatan kerja dengan mutu/kualitas pendidikan yang rendah: (2) Belum semua pendidikan vokasi sebagai pencetak tenaga siap kerja terakui secara legal akan keahlian atau kompetensi lulusannya sehingga yang seharusnya modal utama justru jadi hambatan dalam menyongsong diberlakukannya MEA Saat ini 3) belum terbukanya wawasan bahwa sertiikasi keahlian bagi tenaga pendidik di bidang vokasi dan bagi lulusannya sangat diperlukan. Badan Nasional Sertifikasi profesi sebagai badan negara yang berhak mengelaksanakan sertifikasi profesi belum dapat masuk sepenuhnya di lembaga pendidikan tinggi.

\section{METODE.}

Untuk mengatasi permasalahan yang telah dipaparkan diatas maka solusi yang dapat dilakukan adalah: 1) Meningkatkan mutu/kualitas angkatan kerja melalui peningkatan kualitas lulusan, 2) Penyelenggara pendidikan Vokasi sebaiknya melaksanaakan uji sertiikasi baik bagi peserta didiknya maupun tenaga pendidik dan kependidikan untuk mendapat pengakuan sertifikasi secara legal. 3) Melakukan kerjasama dengan BNSP untuk menyelenggarakan uji sertiikasiuntuk memperoleh pengakuan kompetensi atau keahlian secara legal melalui Badan Nasional Sertifikasi Profesi.

\section{Simpulan}

Menyongsong pelaksanaan masyarakat Ekonomi ASEAN pada tahun 2015 ini, peran lembaga penyelenggara pendidikan khususnya pendidikan vokasi sangatlah penting. Lembaga pendidikan di Perguruan tinggi secara tidak langsung adalah pencetak tenaga kerja yang siap bersaing. Salah satu tolok ukur kualitas lulusan sangat tergantung pada daya saing lulusannya dalam memasuki dunia kerja. Prodi D3 tata busana jurusan Teknologi Industri Fakultas Teknik Universitas Negeri Malang merupakan lembaga penyelenggara pendidikan vokasi ( D3 ) yang dalam tujuan penyelenggaraan prodi D3 sudah merencanakan 
pelaksanaan sertiikasi bagi pendidik dan lulusannya agar mampu bersaing menghadapi MEA 2015, akan tetapi belum merealisasikannya sementara tahun 2015 ini Mea sudah diberlakukan. Oleh sebab itu perlu bekerjasama dengan perguruan tinggi lain dan badan nasional sertiikasi profesi untuk melaksanakan peningkatan kualitas lulusannya.

Daftar Rujukan

Badan Pusat Statistik. laporan Bulanan Data Sosial ekonomi, 2014

Fadli Muhamad, Optimalisasi Kebijakan Ketenagakerjaan dalam menghadapi MEA 2015. Jurnal Rechtsvinding vol 3 no 2, Agustus 2014.

http://nationalgeographic.co.id/berita/2014/12/pahami-masyarakat-ekonomi-asean-mea2015\#

http://www.asean.org/component/itpgooglesearch/search?gsquery=asean+economic+co mmunity

Katalog Jurusan Teknologi Industri. 2012. Malang: Fakultas Teknik UM

Peningkatan Peran Indonesia dalam ASEAN Frameork On Equitable

Economic Development (EED) dalam rangka Ketahanan Nasional. Jurnal kajian

Lemhanas RI edisi 16 November 2013.

Suroso GT, Masyarakat Ekonomi Asean(MEA) dan Perekonomian Indonesia diakses 16 oktober 2015.

http://www.bppk.kemenkeu.go.id/publikasi/artikel/150-artikel-keuanganumum/20545-masyarakat-ekonomi-asean-mea-dan-perekonomian-indonesia 



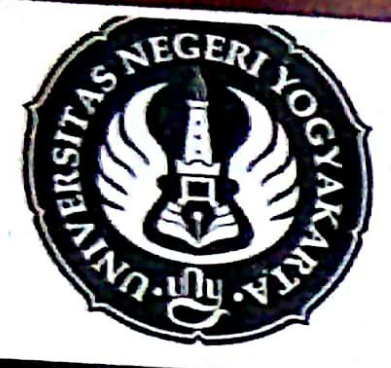

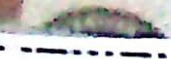

UNIVERSITAS NEGERI YOGYAKARTA

\section{FAKULTAS TEKNIK}

JURUSAN PENDIDIKAN TEKNIK BOGA DAN BUSANA

Alamat : Karangmalang, Yogyakarta 55281 Telp. (0274) 565583

\section{SERTIFIKAT}

1893/UN 34.15/PM/2015

Diberikan Kepada :

Dra. Agus Hery Supadmi Irianti, M.Pd.

\section{Sebagai :}

\section{PEMAKALAH}

Menyiapkan Lulusan D3 Tata Busana Teknologi Industri Fakultas Teknik UM yang Berkualitas

Menyongsong Pemberlakuan Masyarakat Ekonomi Asean (MEA) 2015

Dalam Acara :

Seminar Nasional PTBB 2015

Dengan tema "Pengembangan SDM Kreatif dan Inovatif untuk Mewujudkan Generasi Emas Indonesia Berdaya Saing Global " yang diselenggarakan oleh Jurusan Pendidikan Teknik Boga dan Busana

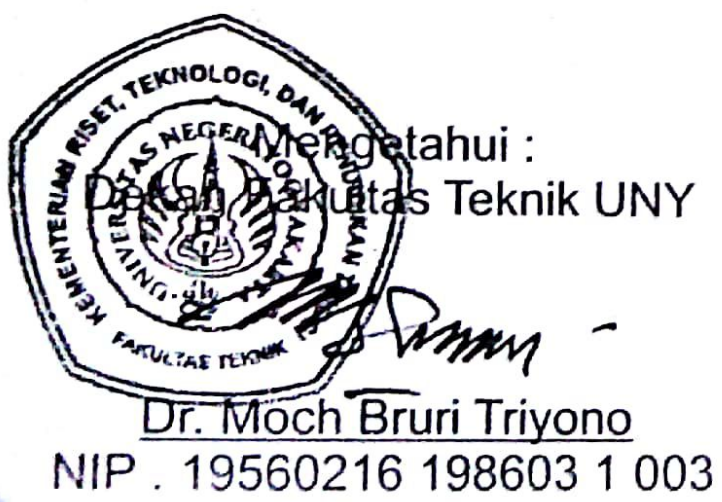

Fakultas Teknik Universitas Negeri Yogyakarta

Minggu, 25 Oktober 2015

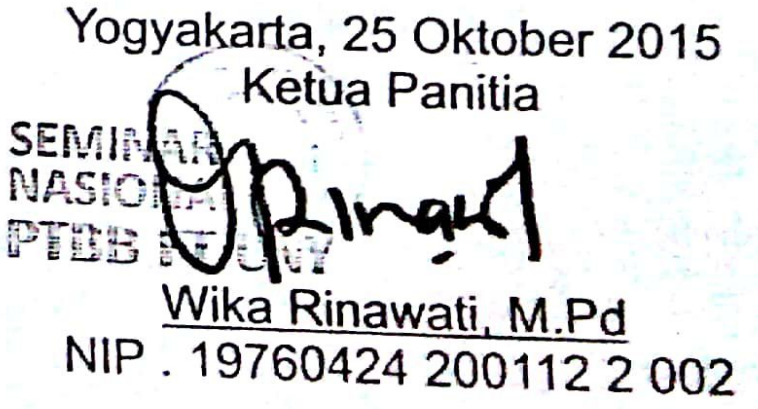

